\title{
Vivências de sofrimento e adoecimento em ambiente de trabalho: uma análise do cotidiano profissional de enfermeiras e enfermeiros num contexto pandêmico em dois centros de referência no atendimento a pacientes de Covid-19
}

\author{
Edmar Aparecido de Barra e Lopes ${ }^{1}$ \\ Universidade Federal de Goiás (Goiânia, GO, Brasil).
}

\begin{abstract}
Este artigo promove um debate que orbita em torno de conceitos, tais como: risco e sofrimento; subjetividade e experiência; cotidiano e memória; vulnerabilidade e precarização. Buscamos compreender as vivências em ambiente de trabalho de enfermeiros e enfermeiras que atuam desde o início da pandemia de Covid-19 (Coronavirus Disease 2019) em dois hospitais públicos de Goiânia, referências no atendimento a indivíduos vitimados pela doença em questão. Destacamos que a realização das entrevistas teve como pano de fundo um contexto de aprofundamento da precarização e da flexibilização das condições e relações de trabalho desses profissionais, associadas ao vertiginoso aumento do número de casos e óbitos entre esses. Com base na história oral temática, constatamos que esses profissionais - embora essenciais no enfrentamento à pandemia - se encontram atualmente ainda mais vulnerabilizados, individual e coletivamente. Ainda que homens e mulheres nessa categoria de trabalhadores experimentem de forma muito diferente o sofrimento e o adoecimento em seus respectivos cotidianos laborais. Particularmente, em função das desigualdades de gênero no mercado de trabalho.
\end{abstract}

Palavras-chave: Covid-19, Pandemia, Risco, Sofrimento, Precarização, Vulnerabilidade.

Experiences of suffering and illness in a work environment: an analysis of nurses daily professional life in a pandemic context in two reference centers in the care of Covid-19 patients

This article discusses concepts such as: risk and suffering, subjectivity and experience; everyday life and memory; vulnerability and precariousness. We analyze the work environment experiences of nurses working since the beginning of the Covid-19 pandemic in two public hospitals in Goiânia, reference hospitals in the care of individuals afflicted by the pathogen in question. The interviews were conducted against a background of deepening in the precariousness and flexibility of working conditions and relationships of these professionals, associated with the vertiginous increase in the number of cases and deaths among them. Based on thematic oral history, we found that these professionals - although essential in facing the pandemic - are currently even more vulnerable individually and collectively, and that men and women of this field experience suffering and illness differently in their respective daily work.

Keywords: Covid-19, Pandemic, Risk, Suffering, Precarization, Vulnerability.

\section{Introdução ao debate}

U ma das principais contribuições da sociologia do risco (Beck, 1992; Beck, Guiddens \& Lash, 1997), no âmbito de uma teoria sobre a sociedade, consiste em questionar o monopólio das ciências naturais no que concerne ao assunto e demonstrar que a vida no atual estágio de desenvolvimento do capitalismo é indissociável do risco individual e social, invisível e global. Nesse sentido, esse conceito é fundamental - associado a outros - a saber: sofrimento; subjetividade; experiência; cotidiano; e memória.

O primeiro destes é baseado na ideia de que o sofrimento psíquico inerente ao trabalho, no âmbito dos modelos de gestão, mantém estreita relação com a construção da identidade (Dejours,

1 https://orcid.org/0000-0001-9576-510X 
2008). O segundo, a ideia de subjetividade tomada enquanto: "a maneira pela qual o sujeito faz a experiência de si mesmo em um jogo de verdade, no qual ele se relaciona consigo mesmo" (Foucault, 2004). O terceiro é o conceito de experiência concebido e articulado criticamente em relação às ideias de classe e de consciência de classe no âmbito das relações de produção e perpassadas por tradições, sistemas de valores, ideias e formas institucionais (Thompson, 1981).

O quarto demarca a categoria de cotidiano compreendida como: "práticas cotidianas ... ações que podem se camuflar num emaranhado de artimanhas silenciosas, sutis, eficientes ... estilo peculiar de trocas, de invenções, de técnicas e de resistência moral". De tal modo "que adquire o status de táticas de resistência" (Certeau, 2008, citado por Bittencourt, 2012, pp. 4-5). O quinto, o constructo de memória, é entendida a partir de suas articulações com a narração e a experiência. Especialmente "os processos de dominação e submissão das diferentes versões e memórias, apontando para a clivagem entre a memória oficial e dominante e 'memórias subterrâneas' marcadas pelo silêncio, pelo não dito, pelo ressentimento" (Pollak, 1989, 1992, citado por Araújo \& Santos, 2007, p. 6). Ressaltando que a importância de cada um desses conceitos tem ganhado centralidade para a compreensão de fenômenos contemporâneos. Inclusive aqueles associados à pandemia causada pela Covid-19 (Coronavirus Disease 2019) ${ }^{2}$.

Ao longo do tempo, o surgimento de epidemias em diferentes sociedades foi determinante para transformar as relações entre os indivíduos, grupos e classes sociais. Nesse sentido, as epidemias estiveram presentes e/ou se intensificaram, particularmente, em épocas ou momentos de crise social (Bertolli, 1986; D’Ávila, 1993). Foi o caso, por exemplo, da peste bubônica, da varíola, da gripe espanhola e da gripe suína (H1N1).

Nessa linha, a pandemia da Covid-19 afeta o mundo, desde o final do ano de 2019 e durante o ano de 2020, impondo mudanças - em maior ou menor grau e com diferentes consequências - na própria organização social, econômica, política etc., em países capitalistas centrais e periféricos. Contribuindo determinantemente para aprofundar diversos tipos de desigualdades preexistentes, tais como aquelas associadas às questões de gênero e raça, de renda, entre outras. Assim, reforçando a vulnerabilidade socioeconômica e civil, esta concebida enquanto "forma como os diferentes indivíduos e grupos sociais têm suas condições de vida ou modos de existência social determinadas pela associação entre trabalho e inserção relacional", de modo a "expandir e a alimentar continuamente a zona de desfiliação" social (Castel, 1995, citado por Kowarick, 2003, p. 47).

As condições de vida e de trabalho de milhões de pessoas em todo o mundo já foram e serão ainda muito afetadas pela pandemia causada pelo novo coronavírus (Sars-CoV-2) causador da Covid-1933, sobretudo pelo aumento do desemprego, da precarização e da flexibilização das relações laborais (Franco, Druck \& Seligmann-Silva, 2010), bem como pelo recrudescimento da pobreza e da extrema pobreza (Organização das Nações Unidas, 2020), além do risco social ainda permanente de adoecimento e morte. Assim, concordamos com Leite (2020), quando afirma que

2 A "Organização Mundial da Saúde (OMS) declarou, em 30 de janeiro de 2020, que o surto da doença causada pelo novo Coronavírus (Covid-19) constitui uma Emergência de Saúde Pública de Importância Internacional - o mais alto nível de alerta da Organização, conforme previsto no Regulamento Sanitário Internacional. Em 11 de março de 2020, a Covid-19 foi caracterizada pela OMS como uma pandemia" (Organização Pan-americana da Saúde, 2020b). Sendo que a crise sanitária associada a esse patógeno, chega no Brasil, sobretudo, em meados do primeiro semestre do mesmo ano, contribuindo para forte agravamento do cenário de crises política, institucional, econômica, já enfrentado pelo governo Bolsonaro.

3 É muito oportuno ressaltar que "a pandemia de Covid-19 terá efeitos arrasadores na economia global, que devem ser mais intensos do que a crise financeira global de 2008, e os países da América Latina e do Caribe não serão poupados". Conforme análise da secretaria executiva da Comissão Econômica para a América Latina e o Caribe (Cepal), Alicia Bárcena, "a crise entrará na história como uma das piores ... que o mundo já passou". Bárcena ainda explica que: "em 2019, o Produtor Interno Bruto (PIB) da região já cresceu a uma taxa de apenas $0,1 \%$. Para 2020, estava previsto um crescimento de 1,3\%, mas agora é esperada uma contração de $-1,8 \%$ ". E "o cenário de recessão pode aumentar o desemprego na região até 10 pontos percentuais. Com esse valor, o número de pobres pode subir de 185 para 220 milhões de pessoas, de uma população total de 620 milhões. A quantidade de pessoas que vivem em extrema pobreza também pode aumentar de 67,4 milhões para 90 milhões" (Organização das Nações Unidas, 2020). 
esta pandemia contribui para explicitar as profundas desigualdades e fragilidades das sociedades capitalistas baseadas em marcadores sociais da diferença, tais como: classe e gênero, raça/etnia e sexualidade, geração e outros.

Nesse contexto, nos chama a atenção, particularmente, a forma como o mercado de trabalho da saúde e a questão dos papéis de gênero, no âmbito desse, são impactados. O que é destacado por Pisani (2020, pp. 2-3), por exemplo, ao reforçar que são principalmente as mulheres "que estão prestando os serviços básicos de saúde e que estão atualmente na linha de frente no combate à Covid-19, logo mais vulneráveis à exposição ao vírus".

Análise reforçada pelo relatório intitulado The State of the World's Nursing 2020 (O Estado da Enfermagem no Mundo 2020), da Organização Mundial da Saúde (OMS), ao ressaltar que: "a) no mundo as mulheres representam a maior parte dos trabalhadores de saúde; b) nas Américas 87\% dos trabalhadores desse setor são mulheres; c) enquanto Brasil, Canadá e Estados Unidos, representam juntos 57\% da população total da região" (Organização Pan-Americana de Saúde, 2020a).

Associada a essa constatação, cabe destacar que, segundo o Conselho Federal de Enfermagem (COFEN) através do Observatório de Enfermagem (Conselho Federal de Enfermagem, 2020b), os(as) profissionais da enfermagem, além de médicos e outros que atuam na área, têm mais contato com os indivíduos com quadros graves da doença causada pelo patógeno em questão. Com efeito, tendem a estar expostos(as) a um risco maior de contraírem o vírus em grande quantidade no corpo, desenvolvendo sintomas mais graves. Uma realidade que pode ser muito agravada, dependendo da faixa etária desses profissionais e de eventuais condições preexistentes, como diabetes, doenças cardíacas etc.

No mesmo sentido, em 19 de maio de 2020, o COFEN já registrava que o Brasil respondia por quase um terço do número de mortes desses profissionais no mundo. Sendo a grande maioria de "mulheres relativamente jovens, com prevalência da faixa etária de 40 a 60 anos, muitas delas com comorbidades e que, portanto, não deveriam estar em contato com casos suspeitos de Covid-19" (Conselho Federal de Enfermagem, 2020a). Enquanto, em 7 de outubro de 2020, o Observatório da Enfermagem (2020b) registrava - no Brasil - 40.820 casos de Covid-19 reportados e um total de 442 óbitos de profissionais. Sendo que 63,12\% dos óbitos registrados entre indivíduos do sexo feminino, e 36,88\% registrados entre indivíduos do sexo masculino.

O maior risco de adoecimento e de morte entre os profissionais de enfermagem no Brasil (e no mundo), portanto, tem um perfil bem definido. Ele é, sobretudo, do sexo feminino e está concentrado na faixa etária entre 40 e 60 anos, conforme indicam os dados oficiais referidos. Acrescentando, como ainda analisaremos, que tal realidade é vivenciada de forma diversa por técnicos(as) de enfermagem e enfermeiros(as).

Nessa linha, a presente análise tem como objetivo identificar e analisar as temporalidades mais recorrentes, bem como a dinâmica dessas, presentes nas narrativas de enfermeiros e enfermeiras que atuam no atendimento a pacientes com quadros de Covid-19. Particularmente, buscar compreender como esses sujeitos experimentam situações cotidianas caracterizadas: 1) pelo agravamento da vulnerabilidade - no contexto em tela - associada a um modelo de gestão e organização do trabalho preexistente causador de sofrimento que, geralmente, se manifesta por meio: do medo e da insegurança; da insatisfação e do desgaste físico; da frustação e da tensão; da angústia e da inquietação; entre outros (Dejours, Abdoucheli \& Jayet, 1994; Mendes, 2012, citados por Tomasi, Gallon, Pauli \& Carvalho, 2019, p. 144); 2) pela intensificação dos riscos de adoecimento e morte, associada ao aprofundamento da precarização das relações e condições de trabalho dessa categoria profissional no contexto em questão (Conselho Internacional de Enfermeiros, 2020). 


\section{Procedimentos metodológicos}

A busca por compreender qualquer fenômeno associado e/ou acentuado pela atual pandemia é muito beneficiada quando lembramos, como esclarece Foucault (1980 citado por Herzog, 1987), que a doença também pode ser considerada como uma construção de fala, ou seja, discursiva. De outro modo, "parte da existência da doença era/é produto de narrativas, das falas ouvidas e registradas". E, nesse processo de construção discursiva da pandemia, é importante considerar "as diferentes vozes que ecoam se aproximam e se distanciam pautadas em interesses de grupos sociais específicos" (Vieira, 2020), inclusive daqueles sujeitos que foram ou são silenciados.

Nessa linha, colocamos a seguinte questão: o que evidenciam as narrativas de enfermeiros(as) que trabalham cotidianamente na linha de frente no atendimento a pacientes com Covid-19? A resposta a essa indagação, central em nossa análise, passa por nossa concordância com Segata (2020, p. 1), quando ressalta que a possibilidade de alcançarmos essa dimensão da doença em questão implica a necessidade de: a) admitirmos inicialmente que "números, estatísticas ou prevalências têm rosto, trajetória e biografia"; b) conferirmos centralidade às "experiências vividas e às sensibilidades coletivas"; c) concordarmos que "fenômenos globais são sempre atuados a partir de contextos locais e a partir de materialidades e práticas situadas".

Portanto, nossa aquiescência com tais pressupostos, constitui-se num fundamento imprescindível para identificação, análise e compreensão dos significados e dinâmicas das principais temporalidades presentes no compósito das narrativas de enfermeiros e enfermeiras, relacionadas a ambientes de trabalho que se configuram extremamente impactados pelo aprofundamento da vulnerabilidade associado a uma dinâmica de intensificação da precarização e flexibilização. Crise agravada pela pandemia, mas que é anterior a tal acontecimento - como foi exposto -, pois foi iniciada por um processo de desinvestimento na área de saúde promovido por políticas neoliberais nas últimas décadas e agora intensificadas no atual governo Bolsonaro.

Nesse sentido, foi imprescindível incorporar o tempo presente, por meio de testemunhos diretos, ao campo da pesquisa e, por consequência, privilegiamos um método de investigação do tipo qualitativo. A metodologia escolhida para precisarmos e compreendermos as principais temporalidades do cotidiano de trabalho desses sujeitos foi a história oral. De acordo com Ferreira (1997), esta não pode ser dissociada de importantes mudanças ocorridas no campo da pesquisa social, particularmente após a Segunda Guerra Mundial, tais como a revalorização da análise qualitativa e a centralidade conferida às experiências individuais e às redes, às situações vividas e aos acontecimentos singulares.

Meihy e Holanda (2007), na mesma linha, esclarecem que a história oral é uma prática que permite produzir narrativas usando meios eletrônicos com o objetivo de - por meio de relatos, testemunhos, - promover análises de processos sociais do presente e facilitar o conhecimento do meio imediato, no que concerne à experiência social de indivíduos e de grupos. Acrescentando que, conforme destacam Amado e Ferreira (1996), a história oral, entendida como metodologia, remete a uma dimensão técnica e a uma dimensão teórica.

Ainda em torno da definição dessa metodologia, Alberti (2004) sublinha que se trata de um método de pesquisa caracterizado por privilegiar a produção de entrevistas como forma de se aproximar do objeto de estudo. De outro modo, trata-se de uma forma de estudar acontecimentos históricos e movimentos sociais, instituições e grupos sociais, além de categorias profissionais, entre outros, à luz de depoimentos de pessoas que deles participaram ou os testemunharam.

Acentuando ainda que essa é uma metodologia associada à ideia de história do tempo presente que institui - por meio de entrevistas orais - novos significados acerca de um passado recente (a partir do final da década de 1990 e início da seguinte), no qual se tornam cada vez mais correntes formas de fragilização da legislação trabalhista e da organização sindical, de sofrimento psíquico e 
adoecimento. Como é o caso das condições de trabalho dos(as) enfermeiros(as) objetos de nossa análise, profundamente reconfiguradas nas últimas décadas.

Quanto à modalidade, optou-se pelo uso da história oral temática. Segundo Meihy (1996) e Queiroz (1988), essa metodologia é caracterizada por sua maior objetividade, uma vez que é desencadeada a partir de um tema previamente estabelecido. Trata-se de um tipo de história oral para a qual as particularidades, as vivências do indivíduo entrevistado, configuram-se como importantes conforme contribuem para o processo de compreensão do tema da pesquisa.

Portanto, a escolha desse procedimento metodológico (e modalidade) de análise crítica e interpretação da realidade justifica-se por três motivos. Primeiro, por termos alcançado adesão por parte dos sujeitos da pesquisa com o uso desse método. Segundo, porque concordamos com Lang (1996) quando defende que, por meio dessa forma de pesquisa com narrativas, podemos delinear as articulações dos sujeitos com os membros de seu grupo, de sua profissão, de sua camada social, da sociedade como um todo. E, terceiro, porque a história oral é um método amplamente reconhecido por conferir centralidade e visibilidade às memórias de excluídos e dos mundos do trabalho (Ferreira, 2002), particularmente de enfermeiros(as) que, enquanto categoria profissional, no atual contexto da pandemia da Covid-19 e governo Bolsonaro, experimentam um de seus momentos históricos mais dramáticos no Brasil.

No âmbito dos princípios basilares do caminho metodológico escolhido, foram produzidas seis entrevistas nos dias 22 e 23 de junho de 2020, além de outras quatro nos dias 24 e 25 do mesmo mês e ano, com enfermeiros e enfermeiras de dois hospitais de referência no atendimento a pacientes com quadros de Covid-19 na cidade de Goiânia: Hospital das Clínicas (HC) e Hospital Estadual Geral de Goiânia Dr. Alberto Rassi (HGG). As sete entrevistas, direta ou indiretamente exploradas, seguem relacionadas:

- Luíza (LZ.), 43. Reside em Goiânia. Formação: técnica em Enfermagem. Trabalha 36 horas no HC como estatutária. Faz horas extras de forma regular, além de plantões (preferiu não nomear o hospital onde faz os plantões). Renda média mensal: $\mathrm{R} \$ 2.700,00$. Trabalha na área de saúde há 13 anos. Entrevista realizada em 22/06/2020, em Goiânia, GO;

- Inês (IS.), 53. Reside em Goiânia. Formação: técnica em Enfermagem. Trabalha 30 horas semanais no HGG como estatutária. Pediu para não revelar o nome do hospital onde faz os plantões. Renda média mensal: $\mathrm{R} \$ 2.000,00$. Trabalha na área há 20 anos. Entrevista realizada em 22/06/2020, em Goiânia, GO;

- Mariana (MN.), 54. Reside em Goiânia. Formação: graduação em Enfermagem e doutorado em Ciências da Saúde. Trabalha 36 horas semanais no HC. Trabalha 30 horas semanais como estatutária na Escola de Saúde Pública da Prefeitura da mesma cidade. Foi contratada, em regime temporário, para atender à demanda de Covid-19. Renda média mensal: $\mathrm{R} \$ 10.500,00$. Trabalha na área há 12 anos. Entrevista realizada em 22/06/2020, em Goiânia, GO;

- Agnaldo (A.), 41. Reside em Goiânia. Formação: graduação em Enfermagem. Trabalha 36 horas semanais como técnico em enfermagem no HC como estatutário. É professor de enfermagem na Pontifícia Universidade Católica de Goiás (PUC-GO) na mesma cidade, 40 horas semanais, contratado através de processo simplificado. Renda média mensal: $\mathrm{R} \$ 13.000,00$. Trabalha na área há 18 anos. Entrevista realizada em 23/06/2020, em Goiânia, GO;

- Mário (MR.), 34. Reside em Goiânia. Formação: graduação em Enfermagem e especialização em Saúde Pública e Terapia. Trabalha 36 horas semanais no HC como técnico em Enfermagem, estatutário. Também trabalha 40 horas semanais no Hospital Regional de Taguatinga (HRT), em Brasília. Renda média mensal: 11.000,00. Trabalha na área há 13 anos. Entrevista realizada em 22/06/2020, em Goiânia, GO; 
- Luciana, 47. Reside em Goiânia. Formação: graduação e mestrado em Enfermagem. Contatada em 05/06/2020. Professora na Pontifícia Universidade Católica de Goiás (PUC-GO). Há 15 anos atuando na área. Desempenhou o papel de "ego" focal;

- Ivete Santos Barreto, 63. Reside em Goiânia. Formação: graduação em Enfermagem e mestrado em Saúde Pública. Enfermeira e professora aposentada da Universidade Federal de Goiás (UFG). Há 42 anos atuando na área. Atualmente, presidente do Conselho Regional de Enfermagem de Goiás (COREN-GO). Entrevistada em 22/06/2020, em Goiânia, GO4.

O que singularizou o pano de fundo dessas entrevistas foi um descontrolado aumento no número de casos e mortes em função da Covid-19 no país. Associada a recorrentes intervenções desastrosas do governo Bolsonaro, num dos momentos mais críticos do Sistema Único de Saúde (SUS) e da sociedade brasileira, tais como: a sobreposição do discurso econômico perante uma calamidade pública histórica; medidas administrativas de base negacionista; e a Medida Provisória no 966, de 13 de maio de 2020, que tentou isentar agentes públicos de responsabilidade civil e administrativa por atos e omissões perante a pandemia (Brasil, 2020).

Ou seja, os depoimentos foram produzidos num contexto no qual o risco de adoecimento e de morte para os profissionais da saúde, e muito mais para enfermeiros e enfermeiras, fora muito intensificado no Brasil.

Cada depoimento do primeiro conjunto durou em média entre 70 e 75 minutos. E cada um do segundo grupo entre 50 e 55 minutos, com exceção de um que se estendeu por aproximadamente 80 minutos. Quanto às transcrições, foram realizadas após todas as entrevistas acontecerem. Obedecendo a questões de ordem ética, como encontramos em Zangelmi (2016), substituímos os nomes de todos(as) entrevistados(as) por pseudônimos objetivando preservá-los de possíveis constrangimentos 5 .

Devemos esclarecer que a produção das referidas entrevistas foi precedida de um mapeamento da população em estudo, a partir de critérios preestabelecidos para seleção dos entrevistados. Sendo que, para tal, optamos pelo sistema de rede (Bott, 1976). De outra forma, uma informante de pseudônimo Luciana, enfermeira que não foi entrevistada por não atender ao perfil da pesquisa, desempenhou o papel de "ego" focal, fornecendo informações sobre sua vivência profissional e também quatro contatos de potenciais depoentes da categoria profissional em questão, que sendo todos posteriormente entrevistados. A partir desse primeiro grupo, alcançamos dados sobre mais nove possíveis indivíduos do segmento em questão e que poderiam ser entrevistados, dentre os quais, apenas seis concordaram com a entrevista. Assim, completamos um número de dez entrevistados(as).

É igualmente importante destacar que, ao realizarmos o total referido de entrevistas com enfermeiros e enfermeiras, não tivemos pretensão de representar o universo desses(as) profissionais que trabalham atualmente no atendimento a pacientes com quadro de Covid-19 na cidade de Goiânia.

As entrevistas foram estruturadas de forma semidirigida e orientadas a partir de um tema central previamente estabelecido, qual seja: o que mudou em sua vida profissional a partir do momento que começou a atender pacientes com Covid-19? Esse, por sua vez, possibilitou um conjunto de outras novas questões associadas e complementares. De tal forma, acessamos experiências e memórias dos enfermeiros e enfermeiras dos dois hospitais públicos de Goiânia, anteriormente referidos, que participaram e/ou participam no atendimento direto a pacientes com quadro de Covid-19.

Além disso, destacamos também que esse conjunto de questões - construídas nessa linha resulta de nosso propósito de privilegiar a ideia de "memórias em disputa" ou "concorrentes"

4 Em função do fato de Ivete Santos Barreto exercer o cargo de presidente do Conselho Regional de Enfermagem de Goiás (Coren-GO), optamos, com sua concordância, por tornar público seu nome na pesquisa, ou seja, não utilizar pseudônimo.

5 As entrevistas foram realizadas pelo autor deste artigo e pela pesquisadora Claudia Naomi Sakashita. Doutora e mestre em Educação pela Faculdade de Educação da Universidade Estadual de Campinas (Unicamp-SP). Graduada em Psicologia (Unesp - Bauru), a qual desenvolveu um papel fundamental também no processo de transcrição das entrevistas, além de conversas informais que contribuíram muito para a problematização de vários aspectos do cotidiano de trabalho desses(as) profissionais. 
(Pollak, 1989) enquanto ponto central para compreendermos a pandemia atual e suas relações com os mundos do trabalho, particularmente, para essa categoria. Em outras palavras, os modos pelos quais esse grande flagelo é "visto de baixo", individual e coletivamente, num movimento de construção das identidades sociais.

Concordando com Rodrigues (2004) quando afirma que se trata de uma perspectiva que impõe a necessidade de uma postura crítica em relação aos tradicionais paradigmas das Ciências Sociais considerados "seguros". E, ao mesmo tempo, um movimento no sentido de privilegiarmos as táticas cotidianas (Certeau, 2008) de temporalização desses(as) enfermeiros(as), enquanto: a) formas de resistências aos espaços panópticos de vigilância (Foucault, 2004) nos quais trabalham; e b) jogos de força (disputas de narrativas) sobre as relações entre pandemia e mundo do trabalho.

Cumpridas todas essas etapas e orientados pela temática central referida, foi iniciada a busca por compreender essas narrativas após o trabalho de transcrição (Queiroz, 1983) mantendo-se as falas tais como ditas. Uma vez que concordamos com a compreensão de que as falas dos(as) entrevistados(as) são perpassadas pela determinação de condições sociais específicas em função de categoria profissional, grupo social ou classe, além de suas crenças, valores e significados (Minayo, 1993).

\section{Notas preliminares à análise das entrevistas}

O impacto da pandemia nas rotinas dos mundos do trabalho configura-se de forma extremamente diversa, reproduzindo e aprofundando inúmeras formas de desigualdades que perpassam historicamente esse universo. Assim, a busca por compreender a atual conjuntura em que os sujeitos trabalhadores encontram-se inseridos exige, sobretudo, nesse primeiro momento, esforços em torno de estudos empíricos e interdisciplinares. Nesse sentido, é fundamental a produção de leituras sobre as vivências relativas às transformações recentes no mundo do trabalho e suas articulações com a ciência, a saúde, a doença, entre outros.

Ao mesmo tempo, consideramos que essas experiências em questão, principalmente as de enfermeiros(as), não podem ser compreendidas descoladas de alterações pelas quais tem passado a economia mundial desde os anos 1970, com a crise do fordismo e a reconfiguração das relações entre trabalho e capital.

Essas alterações ocorreram com consequências para os trabalhadores, tais como: a) aumento da terceirização e heterogeneização crescente com a ampliação do número de mulheres operárias; b) subproletarização, expressa pelas novas modalidades contratuais que implicam em empregos precários e em tempo parcial; c) jornadas mais extensas e intensificação do trabalho; d) maior rotatividade e salários menores; e) arriscadas condições de (in)segurança, dentre outras. Sendo de fundamental importância ressaltar que essas condições mais precárias de trabalho determinam uma outra dimensão, que também expressa a discriminação e a inferioridade dos trabalhadores subcontratados, parte do campo da saúde e segurança no trabalho, pois todas as diferenças referidas anteriormente têm graves implicações sobre as situações de riscos a que são submetidos esses trabalhadores (Antunes, 1999; Seligmann-Silva, 1994; Franco, 2003; Antunes \& Druck, 2013).

Assim, temos que na área da saúde no Brasil, tanto pública quanto privada, tais processos intensificaram-se, impactando de formas distintas homens e mulheres, sobretudo a partir do final dos anos 1990 e início dos 2000. Dessa forma, alimentando o crescimento de velhas e novas modalidades de sofrimento e de adoecimento em ambiente de trabalho (Araújo \& Rotenberg, 2011; Girardi \& Carvalho, 2003; Machado, 1989). Incluindo o recente crescimento vertiginoso do risco de contágio e morte associado à Covid-19.

Importante destacar ainda, de acordo com Machado, Oliveira e Moysés (2010), que até 2020, as enfermeiras, técnicas e auxiliares de enfermagem já totalizavam $80 \%$ da força de trabalho em 
saúde no Brasil. Ressaltando que, em hospitais, estima-se que essas trabalhadoras em enfermagem constituíam, até a mesma data, $60 \%$ da força de trabalho total. Sendo essas relações de trabalho predominantemente precarizadas, inclusive as formais. Ao mesmo tempo, configuradas no âmbito de situações e contextos socio-históricos perpassados por várias questões, tais como: gênero; raça/etnia; classe social etc.

Portanto, os depoimentos que analisaremos não podem ser compreendidos independentemente desse contexto caracterizado pela emergência e consolidação do modelo de Estado neoliberal e suas repercussões sobre os mundos do trabalho. Do mesmo modo, a leitura não pode ser levada a cabo desconsiderando especificidades e tendências - em décadas recentes - do mercado de trabalho em saúde no Brasil. Uma vez que "as mudanças no mundo e nas relações de trabalho . . ., atingem as organizações diretamente . . , envolvem tópicos como construção da identidade, sofrimento, saúde, motivação, percepção de justiça e reciprocidade nas relações intersubjetivas" (Bendassolli \& Borges-Andrade, 2011; Morin, Tonelli \& Piliopas, 2007 citados por Tomasi et al., 2019, p.151).

Uma vez realizadas essas considerações, problematizamos agora a fala dos(as) entrevistados(as), conforme os seguintes tópicos: a) vivências de sofrimento no ambiente de trabalho em tempos de pandemia; b) sofrimento, adoecimento e trabalho entre enfermeiros(as): desigualdades de gênero.

\section{Análise das entrevistas}

\section{Vivências de sofrimento no ambiente de trabalho em tempos de pandemia}

No cotidiano de trabalho dos(as) entrevistados(as), neste contexto da pandemia de Covid-19, constatamos uma recorrência de falas que apontam para o aumento de vivências de sofrimento em ambiente de trabalho. Trata-se da admissão, quase sempre em tom de desabafo, de um cotidiano de trabalho hospitalar no qual esses profissionais denunciam o forte aumento de(o): a) tensão e preocupação; b) nervosismo e pânico; c) dores de cabeça e dificuldades no cumprimento de suas atividades; d) exposição a grande número de mortes e aumento do risco de ser infectado pelo vírus; e) sensação de impotência diante da morte de pacientes e violências na forma de ameaças e ofensas por parte desses e de seus acompanhantes; f) medo de adoecer em função do patógeno em questão e transmitir o vírus a familiares ou amigos; g) estresse, não raramente, decorrente de jornadas de trabalho e plantões exaustivos; h) depressão e insatisfação com o trabalho; i) tristeza e falta de reconhecimento, entre outros.

Portanto, trata-se de uma realidade que já era comum no âmbito das precárias condições de trabalho dessa categoria profissional, mas que foi muito agravada pela pandemia enquanto evento crítico concebido como situação originada de "uma cadeia de incidentes que resulta em uma situação de desastre e emergência". E que acarreta "consequências em termos de interrupção da normalidade da vida diária” (Noal et al., 2016 citados por Tomasi et al., 2019, p. 148). E que, segundo Teixeira e Prebianchi (2019), compromete o desenvolvimento tanto individual quanto institucional na área da saúde.

Nesse sentido, quando Luíza, técnica em enfermagem, é indagada sobre o que mudara em sua vida profissional a partir do momento que começou a atender pacientes com Covid-19, ela nos diz que:

... quando o governo decretou quarentena em março. Então, bateu aquele pânico. Nossa! Eu pensei que fosse surtar no meu primeiro dia, quando eu comecei a trabalhá na quarentena. Bateu muito medo, porque a gente via o que estava passando na televisão, lá na Itália, aquele número enorme de 
mortos, né? Nossa! Eu pensei que fosse surtar . . . , aquilo foi horroroso . . . foi minha semana mais tensa sabe? ... Não tem o que fazer, tem que encarar, aceitar e cuidar (L.).

Essa percepção que a depoente nos apresentou sobre a eclosão da Covid-19, no início de 2020, bem como o modo como a pandemia impactou seu cotidiano de trabalho, está marcada - de forma geral - pelo pânico e medo, pela tensão e impotência: por formas de sofrimento, sobretudo psíquico. Aqui compreendido, conforme Dejours (2008), como fenômeno derivado - particularmente do avanço tecnológico, das novas organizações do trabalho, do aumento das desigualdades e da injustiça social. Sofrimento que parece ter se intensificado em virtude da realidade dessa categoria profissional. Essencial, mas ainda mais precarizada no atual cenário.

Nessa perspectiva, e na linha de Dejours (1992, 2004b), observamos nesse fragmento de depoimento, a dinâmica de um sujeito que parece ter encontrado nas novas condições e relações de seu ambiente de trabalho - neste contexto da pandemia - um fator de detonação e/ou agravamento de seu sofrimento mental. Uma vez que a depoente nos permite concluir que especialmente suas condições de trabalho foram muito comprometidas.

Ao mesmo tempo, essas memórias cotidianas dos trabalhadores da saúde sobre os quais nos debruçamos, em particular as de Luíza, que trabalhara e/ou ainda trabalha no atendimento a pacientes vítimas desse patógeno, não podem ser compreendidas se descoladas desses seus sentimentos perante os riscos em questão e as interfaces desses com representações constituídas e constituintes de temporalidades associadas a valores, tradições e costumes. Por exemplo, quando a depoente emocionada destaca:

Eu cheguei no plantão ... e e para me acalmar, eu li a Bíblia, fui conversar com Deus, foi o que me acalmou (L.).

O sentimento de maior vulnerabilidade da depoente se traduz também em sofrimento nas formas de tensão e preocupação, experimentadas por Luíza em seu ambiente de trabalho. E decorre de um alto risco que, desde o início da pandemia, de várias formas, bate à porta de seu cotidiano de trabalho causando e/ou aumentando na entrevistada o sofrimento psíquico. Tal como constamos, quando ela verbaliza:

Vários colegas meu estão de atestado, colegas mesmo que trabalha junto ..., hoje mesmo duas pessoas saíram de atestado ... dois chegaram a internar .... Teve uma do trabalho ... que era técnica de enfermagem, foi entubada e faleceu ... , ela era obesa e tinha diabete, mas era bem jovem, trinta e poucos anos (L.).

A intensificação do sofrimento nas formas de maior tensão e preocupação não é uma particularidade apenas da fala dessa técnica em enfermagem. Trata-se de elemento comum em nove das dez entrevistas realizadas, embora somente cinco delas sejam objeto de análise neste artigo em função de seu tamanho. Esse sentimento forte de insegurança e preocupação também está presente, por exemplo, num fragmento do depoimento de Inês. Trata-se de outra técnica em Enfermagem, que, respondendo a mesma questão colocada acima:

Fico preocupada com os colegas ... nem todos têm EPI . . já fiz teste 2 vezes . . ., a gente sabe que mesmo quando protegido, é muita gente circulando, a qualquer momento pode pegar de alguém .... Tudo funciona na força . . . tinha dias que não tinha nem máscara nem luvas para trabalhar . . , no final a gente tem que contar é com Deus (IS.).

A depoente revela insegurança e medo não apenas em relação a si, mas também pelos(as) colegas de trabalho que não têm acesso ao Equipamento de Proteção Individual (EPI). O modo 
como vivencia tais formas de sofrimento fica ainda mais claro quando desabafa que não existe uma gestão adequada do ambiente hospitalar e que a falta de proteção no dia a dia de trabalho já era algo comum antes da pandemia, mas se agravou muito no momento atual. E acrescenta que é:

... muito risco de contaminação, porque não é só Covid, é tuberculose, é hepatite, é a AIDS, é tudo!! (IS.).

Quando, entretanto, nos debruçamos sobre a fala de outros(as) profissionais dessa mesma categoria de trabalhadores(as), constatamos diferenças nas maneiras como vivenciam as formas de sofrimento, agravadas pela consciência de estarem expostos(as) ao risco de contágio e morte por Covid-19.

De outra forma, os depoimentos reforçam a análise segundo a qual uma mesma categoria profissional pode ser impactada de maneiras muito distintas pela precarização do trabalho e pelo sofrimento no atual estágio de desenvolvimento do capitalismo.

Uma vez que, como encontramos em Fraser (1983), o prazer ou a satisfação com uma situação ou evento e, por consequência, com o trabalho, é um estado subjetivo muito variável segundo: os diferentes tempos de um indivíduo; as circunstâncias; as influências das forças internas e externas ao ambiente de trabalho. Nessa linha, os impactos da intensificação da precarização e da flexibilização das condições de trabalho sobre o trabalhador, em determinados contextos, estão fortemente relacionados com as formas elaboradas por estes perante tais desafios (Dejours, 1992). De outro modo, pode ocorrer de um mesmo ambiente e forma de organização de trabalho ser fonte de vivências de formas de sofrimento para uma pessoa, mas estar na origem de gratificação e realização, reconhecimento e valorização, para outra (Dejours, 1992; Dejours et al., 1994). Isso fica claramente exposto, por exemplo, quando Mariana relata:

Trabalho na pandemia ..., da mesma forma que eu tenho medo eu tenho coragem, porque eu tenho que trabalhar, porque é da minha profissão, faço o que gosto . . . . Me sinto protegida, sim . . . v vou dizer uma coisa nós temos todas as proteções necessárias, não me falta nada . . . . Eu acho que não existe $100 \%$ de segurança, porque acima de tudo vai depender da minha conscientização, das minhas atitudes e de todos que estão à volta (MN.).

Embora a enfermeira Mariana, no hospital em que trabalha, tenha uma relação de trabalho formalmente mais precária - contrato temporário - do que Luíza e Inês, técnicas de enfermagem, mas estatutárias, ainda assim, a primeira possui renda e escolaridade muito superior as das duas últimas, além do importante fato de que está inserida num ambiente de trabalho muito mais regulado por inúmeros protocolos de segurança: a Unidade de Tratamento Intensivo (UTI).

Essas particularidades ajudam a compreender por que, por um lado, a entrevistada Mariana elabora uma percepção de exposição ao risco perpassada por uma lógica dessacralizada e técnica. E, por outro lado, demonstra se sentir muito mais contente, confiante e realizada em seu ambiente de trabalho. Ao contrário dos processos de rememoração de Luíza e Inês, fortemente marcados por várias formas de sofrimento.

Isso explica, em grande parte, porque Mariana tem uma relação muito diferente com o sentimento de medo, quando comparada com as duas últimas. A ponto de afirmar:

Muitas vezes eu me sinto mais segura no trabalho ..., na rua eu não sei onde aquela pessoa andou o que a pessoa fez, daí me sinto mais exposta (MN.).

Entretanto, devemos destacar que tal percepção deve ser relativizada, pois a depoente também reclama das condições de trabalho: 
Falta funcionário, não tem enfermeiro suficiente para trabalhar nos plantões . . . muitas vezes, nós da enfermagem fazemos papel de médico não tem pessoas em número suficiente, nós trabalhamos com sobrecarga de trabalho (MN.).

Na medida em que avançamos na análise desses depoimentos de profissionais da enfermagem, caracterizados por maior escolaridade e renda e condição ambiental de trabalho menos precária, observamos também o desenvolvimento de determinados mecanismos de defesa, negando e camuflando - inicialmente - o sofrimento durante o atendimento aos pacientes com Covid-19 (Dejours, 1992; Mendes, Merlo, Morone \& Facas, 2010). E muitas vezes, de forma associada a um olhar crítico e irônico sobre o cotidiano de trabalho. Nesse sentido, Agnaldo, ao discorrer sobre os riscos de contágio e morte por Covid-19 em seu ambiente de trabalho relata:

Não sofro com isso . . . . Não tenho medo, porque sigo as normas . . . Porque eu exijo EPI conforme o protocolo de segurança .... O que me causa insegurança é no caso se eu precisar de atendimento .... Então é isso, fico preocupado, tenho medo, se eu vir precisar ou se alguém da minha família vir a precisar (A.).

O processo de rememoração do depoente em questão, ao mesmo tempo, encontra-se associado a uma reflexão crítica sobre o aprofundamento do processo de precarização no ambiente hospitalar em que atua, no contexto da pandemia. Nessa perspectiva, ele relata:

Os profissionais estão se contaminando por falta de treinamento . . . , nos últimos tempos . . . está entrando profissional sem nenhuma experiência, sem nenhum preparo para exercer a função. São pessoas que nunca passaram por hospitais . . . assumindo plantões sem conhecimento técnico. . . O medo, o pânico, a insegurança é gerado pela questão de não ter equipamentos também . . . passamos apuro porque os EPIs não chegam . . . . Até hoje [23/06/2020] não fez exame Covid, somente farão agora por conta da pressão que os funcionários fizeram (depois de tanta briga), mesmo assim, somente farão os testes quem estiver trabalhando direto com Covid, os demais trabalhadores não farão. Pra você ver a gravidade que estamos passando . . . . Então você vê que é precariedade (A.).

Sua percepção sobre os riscos em questão apresenta-se também como testemunho crítico de um modelo de gestão do trabalho hospitalar cotidiano que, sobretudo após o início da pandemia, concorre indiretamente para a produção de cadáveres.

Na mesma perspectiva dos depoentes Mariana e Agnaldo, observamos o desenvolvimento da entrevista com Mário, no que concerne: a) à dinâmica da relação entre vivências de prazer e de sofrimento no trabalho num ambiente hospitalar precarizado; b) a aspectos subjetivos associados a estratégias de defesa frente adversidades organizacionais; c) à negação imediata da percepção do risco como forma de continuar na atividade, de cumprir seu trabalho (Dejours, 2012). Assim, Mário relata:

Não tenho medo ... . Vejo que meus colegas sofrem também com esse medo de pegar Covid, sabe? ... outros estão afastados por Covid . . . , a gente fica mais tenso, estressado. ... Colegas que têm comorbidade, não foram afastado, foram colocados em outra clínica, o que acho mais perigoso, porque atendem pessoal sem saber se tem Covid ou não. . . . O grande problema é a exaustão de trabalho, é um caos, sabe!? . . . A gente tem que resolver tudo, sabe!? . . . No noturno, tá faltando gente para trabalhar. . . Acho que precisa de RH suficiente para atender o pessoal . . . , falta leito, né? . . lugar que cabe quatro leito às vezes tem doze leito (MR.).

Também de forma semelhante a esses depoentes, observamos na sua narrativa uma atitude inicial de percepção da exposição ao risco de contágio e morte em função do patógeno, elaborada 
de forma a individualizar a responsabilidade quanto à menor ou maior possibilidade de tal risco. É o que se evidencia quando ele explica:

A gente precisa ficar é mais atento, né!? Pra mim paciente é paciente, né!? Tem que tenta manter a calma, né!? (MR.).

Destaca ainda, reforçando argumentação daqueles(as) profissionais da enfermagem a ele comparados, ou seja, Mariana e Agnaldo, uma consciência muito crítica relativa à precariedade das condições de trabalho e à situação de extrema vulnerabilidade que ele e seus(suas) colegas de profissão experimentam.

\section{Sofrimento, adoecimento e trabalho entre enfermeiros(as): desigualdades de gênero}

Conforme esclarece Whitaker (1992), a sociologia pode desempenhar um importante papel, visando compreender os impedimentos que a racionalidade de nosso sistema sociocultural cria e alimenta dificultando o processo de integração de alguns indivíduos e grupos sociais. E nesse sentido, refletir sobre as relações entre cultura, doença (transtornos mentais) e o sofrimento psíquico deles resultantes.

E no âmbito dessa, o conceito de gênero - tal como compreendido por Butler (2003), ou seja, como categoria relacional, situacional e passional; frontalmente diferente dos meios de fixação, cristalização e essencialização presentes em outras abordagens de caráter identitário - é fundamental para analisarmos a importância atribuída ao trabalho em nossa sociedade, particularmente a relação entre trabalho, sofrimento e adoecimento entre os sujeitos da pesquisa. Como sabemos, a partir de Heloani e Lancman (2004), para apanharmos as situações causadoras e/ou agravadoras dessas relações, é fundamental conferirmos centralidade às formas de organização social do trabalho e seus impactos na qualidade de vida.

Assim, nossa análise sobre as articulações entre sofrimento, adoecimento e desigualdades de gênero no cotidiano de trabalho dos entrevistados(as) dialoga com a reflexão, segundo a qual o progressivo acúmulo de papéis e exigências relativas ao trabalho feminino em nossa sociedade, tornou a mulher também muito mais angustiada e estressada. Promovendo, de tal forma, instabilidade constante e manifestando-se de formas diversas, sobretudo em conflitos psíquicos. Entre os quais a dor e a somatização enquanto sintomas e sinais corporais de desequilíbrios psicossociais articulados a processos de banalização da injustiça social (Dejours, 1999).

Esse olhar é ainda mais esclarecedor dessas relações, ao ressaltar que os empregos precários, subvalorizados e expostos a inúmeros riscos estão concentrados entre as mulheres. E que mudanças organizacionais nesses trabalhos, muitas vezes, passam a inviabilizar a aplicação da inteligência e a realização profissional, comprometendo a própria construção da identidade do indivíduo (Dejours, 1992; Dejours, 2004a). Assumindo, desse modo, um papel preponderante na dinâmica de sofrimento e do adoecimento no trabalho (Merlo, 2006). Nesse sentido, Inês, técnica em Enfermagem, relata:

Quando instalaram as O.S. lá no hospital, eu tive depressão, porque eu gostava muito do atendimento ao paciente.... Na verdade, eu me senti inútil porque eu gostava muito do meu trabalho, de repente o médico vem e fala para você: você não está atendendo às necessidades do hospital. . . Porque eu fazia um turno de 12 por 60 e as enfermeiras que estavam trabalhando pela O.S. faziam relatório de pé, ou seja, nem parava direito para fazer relatório.... Eu trabalhava 12 horas de pé e não podia nem sentar para fazer relatório, até tiraram as cadeiras da unidade ... Tinha que fazer de pé e meu pé doía ..., porque eu sou gordinha sabe!? Aí eu inchava no final do plantão, daí eu tinha que passar mais vezes com o médico. ... Daí chegou um dia que o médico chegou para mim e falou olha a senhora não vai atender às necessidades da O.S., eles vão 
colocar pessoas mais jovens, que vão dar conta de ficar 12 horas de pé... . Tudo isso foi uma bomba para minha cabeça porque eu gostava do trabalho e queria continuar (IS.).

Importante destacar que no contexto de precarização e flexibilização do mercado de trabalho, intensificados a partir de meados da década de 1970, aumentaram as desigualdades de gênero no mercado de trabalho em geral. Do que resultou o fenômeno do maior adoecimento de mulheres por conta do trabalho.

Nesse sentido, cabe ressaltar que todas as entrevistadas que trabalham em diferentes funções no âmbito da enfermagem relataram já ter necessitado e obtido atestado ou licença em função de alguma doença do trabalho, uma ou mais vezes. O relato de Mariana, enfermeira, é muito esclarecedor desse processo:

Eu acho que aumentou muito as doenças aqui entre as meninas ..., e a maior parte acho que é mental mesmo ... . Nós temos muitos problemas psicológicos . . . também problemas de coluna, problemas de articulação, artrites ... tem uma incidência muito grande no nosso grupo de trabalho. . . É porque, assim, está tendo muita cobrança, sabe? Diminuiu a equipe de trabalho e aumentou o volume de trabalho para aqueles que continuam. . . . Então, assim, a sobrecarga está muito grande pra a gente. . . . Sempre foi muito precário e agora agravou ... . já tínhamos o problema de superlotação de pacientes que agora agravou (MN.).

Isso deve ser compreendido tomando em conta o fato de que - segundo Bruschini (2006) o ingresso das mulheres no mundo econômico se realiza de forma assimétrica. Dessa forma, também criando impedimentos para o desenvolvimento profissional delas e reforçando a impossibilidade de carreiras contínuas e, por conseguinte, empregos de melhor qualidade. E aumentando a exposição a riscos de adoecimento. Nessa linha, Agnaldo, enfermeiro, relata:

Muitas colegas estão se contaminando por falta de treinamento . . . elas não são treinadas . . . e são colocadas para atender .... Para você colocar equipamento, para você tirar equipamento, tem que ter todo o cuidado. Outro dia uma enfermeira recém-contratada tava entrando na ala de Covid sem a máscara MF2 .... Ela entrou com a máscara simples para prestar um atendimento . . . daí eu chamei para ela voltar, chamei atenção dela e ela me respondeu: olha eu achei que eu estava devidamente paramentada ... Então você vê que é precariedade, é falta de conhecimento, é falta de treinar, falta supervisão (A.).

As desigualdades de gênero e o fenômeno do maior adoecimento de mulheres em virtude do trabalho também têm relações muito estreitas com as formas de violência laboral. Barreto (2000) e Hirigoyen (2001) esclarecem que as discrepâncias no que tange às relações de gênero, estão entre os principais motivos das formas de violências presentes no ambiente de trabalho: atentados contra a dignidade e o uso da violência verbal, física ou sexual. O que está evidenciado, por exemplo, na fala de Luíza, técnica em enfermagem:

... então são várias formas de violência e que aumentaram com a Covid, mas..., parece que as mulheres, elas acabam sendo mais vítimas do que os homens.... A gente vê mais relatos de mulher queixando ... , a violência é maior contra a profissional mulher. . . . A última agressão física que eu sofri . . . tava um movimento grande, paciente esperando e aí se revoltou pela espera, pela demora .... Em quem que ele foi bater? Na mulher. .. A violência que nós estamos passando é constante, a violência verbal e, às vezes, até a física, é uma constante entre nós.... Da parte dos acompanhantes, pacientes.... E com a pandemia ..., as pessoas estão mais nervosas, mais agressivas.... Precisamos de respeito, de segurança.... É constante a gente vê queixa de colegas com crise: ansiedade, depressão . . . , síndrome do pânico, ansiedade, crises de choro (LZ.). 
Assim, fica claro que o maior sofrimento e adoecimento de mulheres por conta do trabalho, como sugerem as entrevistas realizadas, não pode ignorar as diferenças relativas aos modos como homens e mulheres são incorporados ao mercado de trabalho. Nesse sentido, como ressalta Hirata (2018), a compreensão de tal fenômeno passa pela necessidade do reconhecimento e análise crítica de questões de gênero associadas a outras como classe e relações raciais, que perpassam o mundo do trabalho. Particularmente, a divisão sexual: do trabalho profissional e do doméstico; do poder e do saber na sociedade.

\section{Considerações finais}

Este estudo objetivou, por meio da história oral temática, demonstrar como o atual contexto pandêmico tem impactado o cotidiano de trabalho de enfermeiros e enfermeiras que trabalham em dois hospitais, referências no atendimento a pacientes com Covid-19 na cidade de Goiânia. E como esses sujeitos têm experimentado este processo. Entre as principais conclusões resultantes da pesquisa encontramos que estes sujeitos têm vivenciado - de forma diversa - processos que podem ser traduzidos na percepção da intensificação da precarização e flexibilização das condições e relações de trabalho. Sendo que tais efeitos, sobre o modelo de gestão e organização do trabalho preexistentes, têm resultado - de forma geral - na ampliação de vivências de sofrimento e adoecimento por trabalhadores(as) em ambiente de trabalho.

Os sujeitos entrevistados, de forma geral, relataram que a pandemia afetou suas vidas em todas as dimensões - particularmente - no ambiente de trabalho. Entre as principais formas de sofrimento evidenciadas, estão: a) tensão e preocupação; b) nervosismo e pânico; c) insegurança e medo; d) sensação de impotência e aumento de estresse; e) desgaste físico e frustação; f) tristeza etc. Por outro lado, desponta como uma das formas mais relatadas de adoecimento nesse cenário: a depressão e o contágio pelo coronavírus.

A pesquisa revelou também que o modo como esses profissionais estão inseridos em seus respectivos ambientes de trabalho é fundamental para a compreensão relativa às formas como eles vivenciam a dinâmica do sofrimento no âmbito do trabalho e - não raro - o adoecimento. Nesse sentido, observamos que variáveis como escolaridade, função desempenhada no ambiente hospitalar e renda são determinantes na constituição das formas como esses(as) trabalhadores respondem ao referido processo de deterioração das condições de trabalho neste momento pandêmico.

A análise das entrevistas comprovou também que os diferenciais de gênero no mercado de trabalho brasileiro não podem ser ignorados quando tentamos compreender os principais modos como os indivíduos dessa categoria profissional experimentam as transformações que ocorrem nos ambientes hospitalares em que atuam. De outra forma, não apenas verificamos que enfermeiros e enfermeiras sofrem e adoecem de formas distintas nessa conjuntura, mas também que principalmente elas, as enfermeiras (em seus diversos níveis), sofrem e adoecem mais.

Reforçando, assim, uma realidade amplamente documentada pela literatura especializada nacional e internacional marcada pela constatação da: a) ampliação precária da força de trabalho feminina na enfermagem; b) modernização de gestão hospitalar acompanhada de permanências relativas à discriminação de mulheres em ambiente de trabalho; c) persistência de formas de subvalorização de ocupações femininas nessa profissão; d) continuidade e até mesmo aumento de formas de violência laboral perpetradas principalmente por médicos(as), pacientes, acompanhantes de pacientes; e) entre outros.

Ressaltamos que umas das principais dificuldades enfrentadas no desenvolvimento deste estudo foi convencer os entrevistados a participarem da pesquisa realizada num momento de vertiginoso aumento do número de casos e óbitos, principalmente entre enfermeiras. Geralmente reclamando 
da falta de tempo, sobrecarga de trabalho ou ainda simplesmente não desejando falar sobre o tema, os contatados não se apresentavam dispostos(as) ou confortáveis em colaborar com esta.

Uma das principais contribuições resultantes, desta pesquisa, chama a atenção para o fato de que esses(as) profissionais, embora essenciais no enfrentamento à pandemia, se encontram atualmente ainda mais vulnerabilizados individual e coletivamente. $\mathrm{E}$, ainda, para a necessidade de conferirmos centralidade, na análise desse fenômeno, às interfaces entre desigualdades de gênero, sofrimento e adoecimento.

Novos estudos sobre o tema serão necessários também - por exemplo - para analisar questões que os limites deste artigo não permitiram, tais como os principais sentidos do trabalho para enfermeiros(as) no âmbito da pandemia. É igualmente importante nos perguntarmos, em novas análises, sobre as estratégias defensivas (individuais e coletivas) mais comumente desenvolvidas por esses profissionais em ambiente de trabalho. Novos esforços, na mesma perspectiva, são necessários para buscarmos compreender como dinâmicas relacionadas a valores e mitos sobre essa profissão, conflitos de classes e relações raciais, atuam na dinâmica sofrimento-prazer-trabalho vivenciada por esses(as) profissionais.

\section{Referências}

Alberti, V. (2004). Manual de história oral (2ae ed.). Rio de Janeiro: Editora FGV.

Amado, J. \& Ferreira, M. de M. (Orgs.). (1996). Usos e abusos da história oral. Rio de Janeiro: Editora FGV.

Antunes, R. (1999). Os sentidos do trabalho: ensaio sobre a afirmação e a negação do trabalho. São Paulo: Boitempo.

Antunes, R. \& Druck, G. (2013). A terceirização como regra?. Revista do Tribunal Superior do Trabalho, 79(4), 214-231. Recuperado de https://juslaboris.tst.jus.br/bitstream/handle/20.500.12178/55995/011_ antunes_druck.pdf?sequence $=1$

Araújo, T. M. \& Rotenberg, L. (2011). Relações de gênero no trabalho em saúde: a divisão sexual do trabalho e a saúde dos trabalhadores. In A. A. Assunção \& J. Brito (Orgs.), Trabalhar na saúde: experiências cotidianas e desafios para a gestão do trabalho e do emprego (pp. 131-150). Rio de Janeiro: Editora Fiocruz.

Araújo, M. P. N. \& Santos, M. S. (2007) História, memória e esquecimento: implicações políticas. Revista Crítica de Ciências Sociais, 79, 95-111. Recuperado de https://journals.openedition.org/rccs/728

Barreto, M. (2000). Uma jornada de humilhações. Dissertação de Mestrado, Pontifícia Universidade Católica, São Paulo SP, Brasil.

Beck, U. (1992). Risk society: towards a new modernity. Londres: Sage.

Beck, U., Giddens, A. \& Lash, S. (1997). Modernização reflexiva: política, tradição e estética na ordem social moderna. São Paulo: Editora Unesp.

Bendassolli, P. F. \& Borges-Andrade, J. E. (2011). Significado do trabalho nas indústrias criativas. Revista de Administração de Empresas, 51 (2), 143-159. Recuperado de https://www.scielo.br/pdf/rae/v51n2/v51n2a03.pdf

Bertolli, C. (1986). Epidemia e sociedade. A gripe espanhola no município de São Paulo. Dissertação de Mestrado, Universidade de São Paulo, São Paulo. SP, Brasil

Bittencourt, M. I. G. de F. (2012). Michel de Certeau 25 anos depois: atualidade de suas contribuições para um olhar sobre a criatividade dos consumidores. Polêmica, 11(2), 185-192. Recuperado de https://www.e-publicacoes.uerj.br/ index.php/polemica/article/view/3091/2210

Bott, E. (1976). Família e rede social. Rio de Janeiro: Francisco Alves.

Brasil. (2020).Medida Provisórian. 966, de 13 de maio de 2020. Dispõe sobre a responsabilizaçãode agentes públicos por açãoe omissão em atos relacionados com a pandemia da Covid-19. Recuperado de https://www.congressonacional.leg.br/ materias/medidas-provisorias/-/mpv/141949 
Bruschini, C. (2006). Trabalho doméstico: inatividade econômica ou trabalho não remunerado? Revista Brasileira de Estudos de População, 23(2), 331-53. Recuperado de https://www.scielo.br/scielo.php?script=sci_ arttext\&pid=S0102-30982006000200009

Butler, J. P. (2003). Problemas de gênero: Feminismo e subversão da identidade (Renato Aguiar, Trad.). Rio de Janeiro: Civilização Brasileira.

Certeau, M. (2008). A invenção do cotidiano: 1. Artes de fazer. Petrópolis, RJ: Vozes.

Conselho Federal de Enfermagem. (2020a). Brasil responde por 30\% das mortes de profissionais de Enfermagem por Covid-19.

Recuperado de http://www.cofen.gov.br/brasil-responde-por-30-das-mortes-de-profissionais-de-enfermagempor-covid-19_80622.html

ConselhoFederal de Enfermagem. (2020b). Observatório da enfermagem. Recuperado de http://observatoriodaenfermagem. cofen.gov.br/

Conselho Internacional de Enfermeiros. (2020). More than 600 nurses die from Covid-19 worldwide. Recuperado de https://www.icn.ch/news/more-600-nurses-die-covid-19-worldwide

Dávila, B. E. (1993). La gripe española. La pandemia de 1918-1919. Madrid: Siglo XXI.

Dejours, C. (1992). A loucura do trabalho: estudo de psicopatologia do trabalho. São Paulo: Cortez-Oboré.

Dejours, C. (1999). A banalização da injustiça social (L. A. Monjardim Trad.). Rio de Janeiro: Editoria FGV.

Dejours, C. (2004a). Activisme professionnel: masochisme, compulsivité ou alienation? Travailler, 1(1), 25-40. Recuperado de https://www.cairn.info/revue-travailler-2004-1-page-25.htm\#

Dejours, C. (2004b). Prefácio. In S. Lancman \& L. I. Sznelwar. Christophe Dejours: da psicopatologia à psicodinâmica do trabalho. Rio de Janeiro: Editora Fiocruz; Brasília: Paralelo 15.

Dejours, C. (2008). Addendum: da psicopatologia à psicodinâmica do trabalho. In S. Lancman \& L. I. Sznelwar (Orgs.), Christophe Dejours: da psicopatologia à Psicodinâmica do Trabalho (pp. 47-75). Brasília: Paralelo 15.

Dejours, C. (2012). A psicologia das massas sob a perspectiva da clínica do trabalho. In C. Dejours. Trabalho vivo. Trabalho e emancipação (pp. 35-57). Brasília: Paralelo 15.

Dejours, C., Abdoucheli, E. \& Jayet, C. (1994). Psicodinâmica do trabalho: contribuições da escola dejouriana à análise da relação prazer, sofrimento e trabalho. São Paulo: Atlas.

Ferreira, M. de M. (1997). História oral, comemorações e ética. Projeto história. Ética e História oral, (15), 157-164. Recuperado de http://cpdoc.fgv.br/producao_intelectual/arq/518.pdf

Ferreira, M. de M. (2002). História, tempo presente e história oral. Topoi, 3(5), 314-332. Recuperado de https://www.scielo.br/pdf/topoi/v3n5/2237-101X-topoi-3-05-00314.pdf

Fraser, T. M. (1983). Human stress, work and job satisfaction: a critical approach. Geneva: International Labour Office.

Foucault, M. (2004). Vigiar e punir. O nascimento da prisão. Petrópolis, RJ: Vozes.

Franco, T. (2003). Trabalho alienado: habitus e danos à saúde humana e ambientais ( $O$ trabalho entre o céu, a terra e a história). Tese de Doutorado, Universidade Federal da Bahia, Salvador, BA, Brasil.

Franco, T., Druck, G. \& Seligmann-Silva, E. (2010). As novas relações de trabalho, o desgaste mental do trabalhador e os transtornos mentais no trabalho precarizado. Revista Brasileira de Saúde Ocupacional, 35(122), 229-248.

Girardi, S. M. \& Carvalho, C. L. (2003). Configurações do mercado de trabalho dos assalariados em saúde no Brasil. Recuperado de https://www.nescon.medicina.ufmg.br/biblioteca/imagem/0849.pdf

Heloani, R. \& Lancman, S. (2004). Psicodinâmica do trabalho: o métodoclínico de intervençãoe investigação. Production, 14(3), 77-86. Recuperado de https://www.scielo.br/scielo.php?pid=S0103-65132004000300009\&script $=$ sci_ abstract\&tlng $=\mathrm{pt}$

Herzog, R. (1987). Sujeito-da-doença ou doença do sujeito? A construção do ser doente. Dissertação de Mestrado, Pontifícia Universidade Católica, Rio de Janeiro, RJ, Brasil.

Hirata, H. (2018) Classe, gênero, raça e movimentos sociais: a luta pela emancipação. Revista de Políticas Públicas, 22, 6-18. Recuperado de http://www.periodicoseletronicos.ufma.br/index.php/rppublica/article/view/9779

Hirigoyen, M. F. (2001). Le malaise dans le travail, harcèlement moral: démêler le vrai du faux. Paris: Syros.

Kowarick, L. (2003). Sobre a vulnerabilidade socioeconômica e civil: Estados Unidos, França e Brasil. Revista Brasileira de Ciências Sociais, 18(51), 61-85. Recuperado de http://www.scielo.br/pdf/rbcsoc/v18n51/15986.pdf 
Lang, A. B. da S. G. (1996). História oral: muitas dúvidas, poucas certezas e uma proposta. In J. C. S. B. Meihy (Org.), (Re) introduzindo história oral no Brasil (pp. 31-48). São Paulo: Xamã.

Leite, K. C. (2020). A (in)esperada pandemia e suas implicações para o mundo do trabalho. Psicologia E⿱ Sociedade, 32, 1-18. Recuperado de https:/www.scielo.br/scielo.php?pid=S0102-71822020000100408\&script=sci_arttext

Machado, M. H. (1989). A mão de obra feminina no setor saúde no Brasil. In E. Labra (Org.), Mulher, Saúde e Sociedade no Brasil (pp. 119-134). Petrópolis, RJ: Vozes; Rio de Janeiro: Abrasco.

Mendes, A. M., Merlo, A. R. C., Morone, C. F. \& Facas, E. P. (Orgs.), (2010). Psicodinâmica e Clínica do Trabalho: temas, interfaces e casos brasileiros. Curitiba: Juruá.

Meihy, J. C. S. B. (1996). Manual de história oral. São Paulo: Edições Loyola.

Meihy, J. C. S. B. \& Holanda, F. (2007). História oral: como fazer, como pensar. São Paulo: Contexto.

Merlo, A. R. C. (2006). Doenças do trabalho. In L. Holzmann \& A. D. Cattani (Orgs.), Dicionário de Trabalho e Tecnologia (pp. 74-96). Porto Alegre: Editora da UFRGS.

Minayo, M. C. de S. (1993). O desafio do conhecimento. Pesquisa qualitativa em saúde. São Paulo: Hucitec; Rio de Janeiro: Abrasco.

Observatório da Enfermagem. (2020). Profissionais infectados com Covid. Recuperado de http://observatoriodaenfermagem. cofen.gov.br/

Organização das Nações Unidas. (2020). Economia da América Latina e Caribe sofrerá efeitos "arrasadores" do novo Coronavírus. Recuperado de https://news.un.org/pt/story/2020/03/1708042

Organização Pan-Americana da Saúde. (2020a). Em meio à pandemia de Covid-19, novo relatório da OMS pede investimento urgente em profissionais de enfermagem. Recuperado de https://www.paho.org/bra/index. php?option $=$ com_content\&view $=$ article $\& i d=6139$ :em-meio-a-pandemia-de-covid-19-novo-relatorio-daoms-pede-investimento-urgente-em-profissionais-de-enfermagem\&Itemid $=812$

Organização Pan-Americana da Saúde. (2020b). Folha informativa Covid-19 - Escritório da OPAS e da OMS no Brasil. Recuperado de https://www.paho.org/bra/index.php?option=com_ content $\&$ view $=$ article $\& i d=6101:$ covid19\&Itemid $=875$

Pisani, M. da S. (2020). O enfrentamento e a sobrevivência ao Coronavírus também precisa ser uma questão feminista! Boletim Cientistas sociais e o Coronavirus, (12). Recuperado de http://anpocs.com/images/stories/boletim/boletim_ CS/Boletim_n12.pdf

Poder 360. (2020). Coronavírus. Recuperado de https://www.poder360.com.br/tag/departamento-de-doencasemergentes-da-oms/?

Pollak, M. (1989). Memória, esquecimento, silêncio. Estudos Históricos, 2(3), 3-15. Recuperado de http://www.uel.br/ cch/cdph/arqtxt/Memoria_esquecimento_silencio.pdf

Queiroz, M. I. P. (1983). Variações sobre a técnica do gravador no registro da informação viva (2 ${ }^{\underline{a}}$ ed.). São Paulo: CERVE; FFLCH/USP.

Queiroz, M. I. P. (1988). Relatos orais: do indizível ao dizível. In O. M. Von Simon (Org.), Experimentos com História de Vida (Itália-Brasil). São Paulo: Vértice.

Rodrigues, H. de B. C. (2004). O homem sem qualidades. História oral, memória e modos de subjetivação. Estudos e Pesquisas em Psicologia, 2(2), 24-46. Recuperado de http://pepsic.bvsalud.org/pdf/epp/v4n2/v4n2a03.pdf

Segata, J. (2020). Covid-19: escalas da pandemia e escalas da antropologia. Boletim Cientistas sociais e o Coronavírus, (2). Recuperado de http://anpocs.com/images/stories/boletim/boletim_CS/Boletim_n2.pdf

Seligmann-Silva, E. (1994). Desgaste mental no trabalho dominado. São Paulo: Cortez.

Symon, G. (2004). Qualitative research diaries. In C. Cassel \& G. Symon (Orgs.), Essential guide to qualitative methods in organizational research (pp. 76-89). London: Sage.

Teixeira, F. D. \& Prebianchi, H. B. (2019). Comprometimento, estresse e satisfação com a vida de profissionais da saúde. Revista Psicologia Organizações e Trabalho, 15(4), 598-606. Recuperado de http://pepsic.bvsalud.org/pdf/ rpot/v19n2/v19n2a04.pdf

Thompson, E. P. (1981). A miséria da teoria ou um planetário de erros: uma crítica ao pensamento de Althusser. Rio de Janeiro: Zahar. 
Tomasi, M., Gallon, S., Pauli, J. \& Carvalho, R. (2019). O sentido do trabalho para bombeiros pós-evento crítico: o caso da Boate Kiss. Cadernos de Psicologia Social do Trabalho, 22 (2), 143-163. Recuperado de http://www.revistas.usp.br/ cpst/article/view/158967/160707

Vieira, A. O. (2020) O direito de fala e de memória na epidemia. Boletim Cientistas sociais e o Coronavírus, (30). Recuperado de http://anpocs.com/images/stories/boletim/boletim_CS/Boletim_n30.pdf

Whitaker D. (1992). Cultura e doença mental. In D'Incao M. A. (Org.), Doença mental e sociedade: uma discussão interdisciplinar (pp. 67-85). Rio de Janeiro: Graal.

Zangelmi, A. J. (2016). Pesquisadores e entrevistados: problemas éticos ligados a contextos de desigualdade e à atuação de movimentos sociais. História Oral, 19(1), 129-148. Recuperado de http://revista.historiaoral.org.br/index. php journal $=$ rho\&page $=$ issue $\& o p=$ view $\&$ path $\% 5 B \% 5 D=38$

\section{Endereços para correspondência}

ed.clio@hotmail.com
Recebido em: 13/07/2020

Revisado em: 20/10/2020

Aprovado em: 21/10/2020 